\title{
Dearomatization of Electron-Deficient Nitrogen Heterocycles via Cobalt-Catalyzed Asymmetric Cyclopropanation
}

\author{
Amruta Joshi-Pangu, Ryan D. Cohen, Matthew T. Tudge and Yonggang Chen* \\ *E-mail: Yonggang.chen@merck.com.
}

\section{S1. Crystal Data and Structure Refinement for Compound 15 (CCDC 1432596)}

A single crystal grown from chlorobenzene was selected for single crystal X-ray data analysis. The crystal was a small elongated needle with dimensions of $0.15 \mathrm{~mm} \times 0.05 \mathrm{~mm} \times 0.03 \mathrm{~mm}$. Data collection was performed on a Bruker Apex II system at $100 \mathrm{~K}$. The unit cell was determined to be orthorhombic in space group P $2{ }_{1} 2_{1} 2_{1}$. The structure contained two molecules in the crystallographic asymmetric unit. Crystallographic data is summarized in Table S1. Figure S1a shows an ORTEP representation of Compound 15 with thermal ellipsoids set at the 50\% probability level. Figure S1b shows one molecule from the asymmetric unit to better visualize the stereogenic centres. Absolute configuration is established by anomalous-dispersion effects in diffraction measurements on the crystal and is as depicted in Scheme S1. Coordinates, refinement details and structure factors have been deposited with the Cambridge Crystallographic Data Centre (CCDC 1432596).

Figure S1a: ORTEP representation of Compound 15 with thermal ellipsoids set at the $50 \%$ probability level.

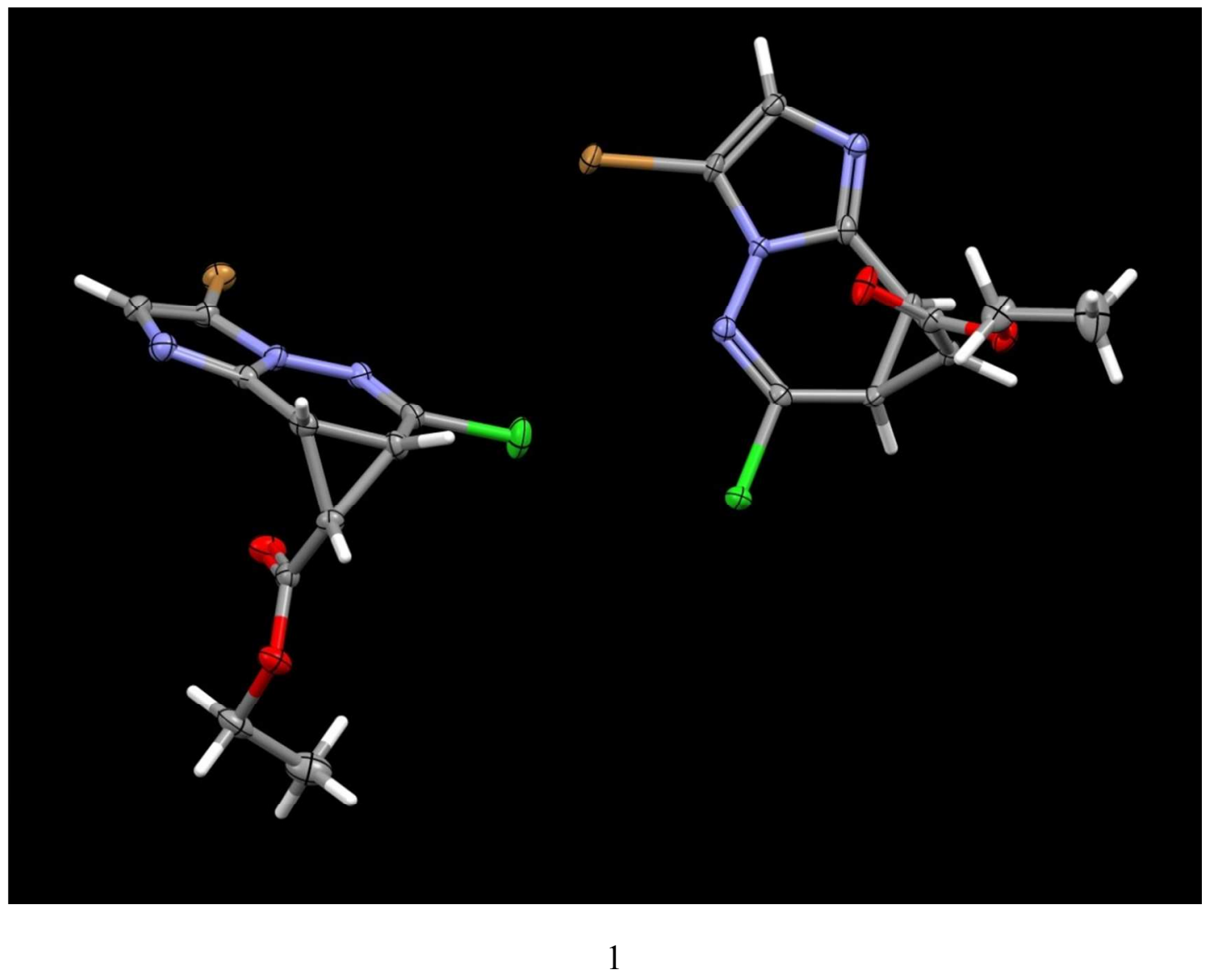


Figure S1b: ORTEP representation of Compound 15 with thermal ellipsoids set at the 50\% probability level. Only one molecule of the two in the asymmetric unit is depicted.

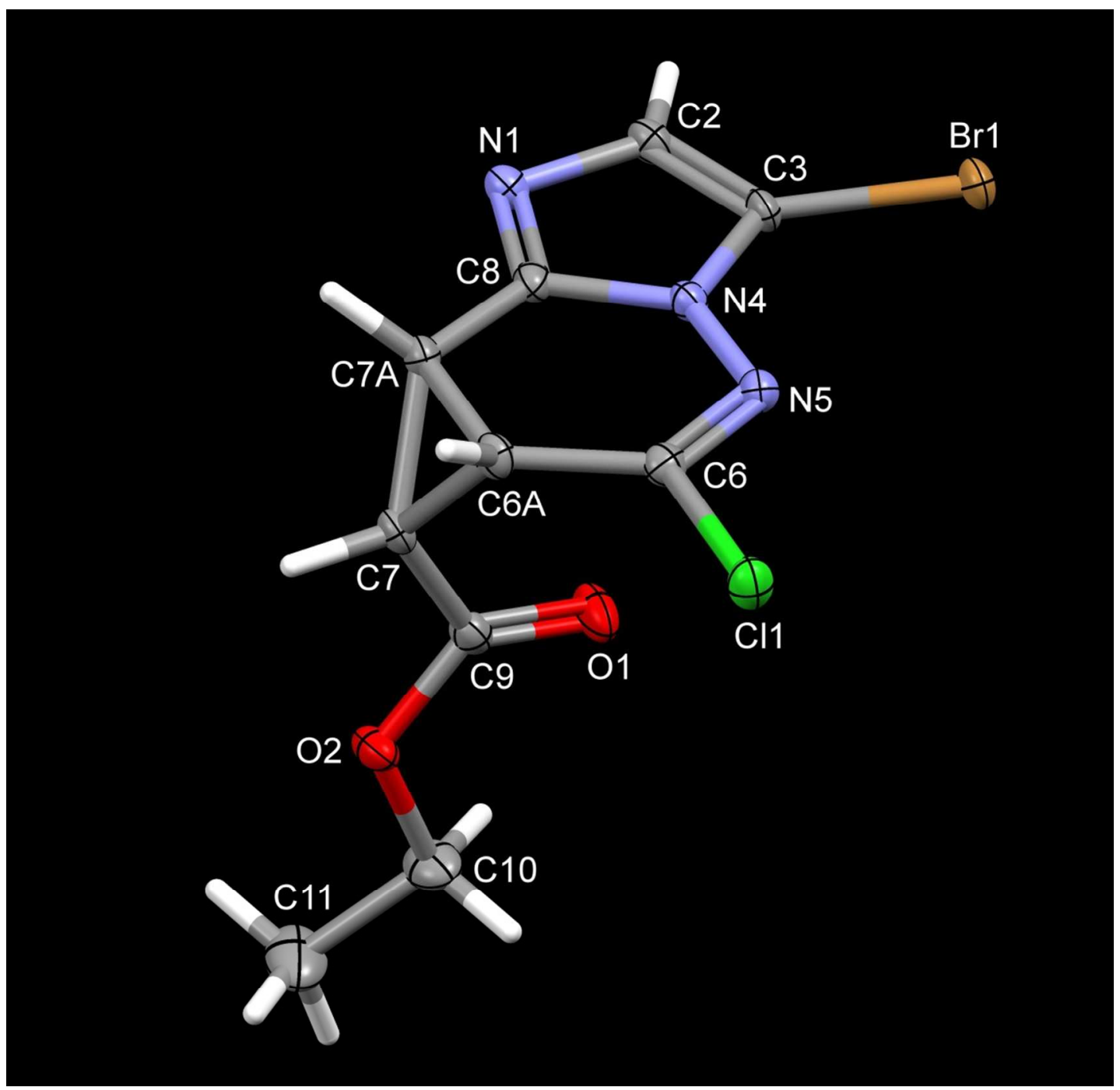

Scheme S1: Compound 15

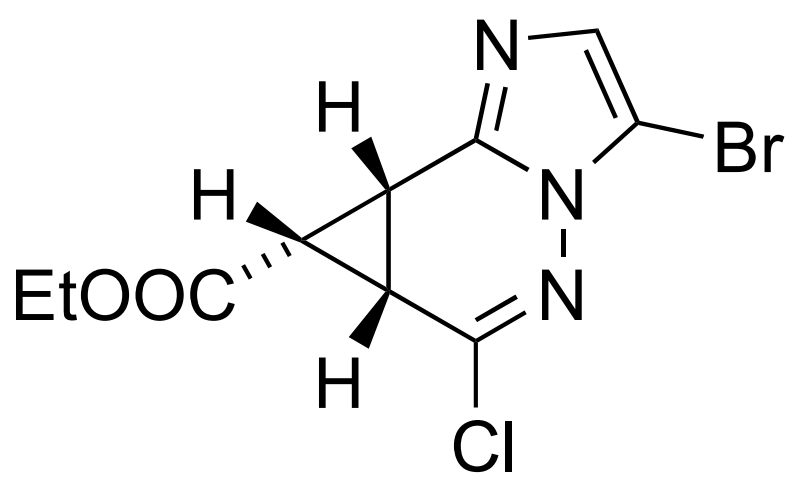


Table S1. Crystal Data and Structure Refinement for Compound 15 [CCDC 1432596]

Identification code

Empirical formula

Formula weight

Temperature

Wavelength

Crystal system

Space group

Unit cell dimensions

Volume

Z

Density (calculated)

Absorption coefficient

$\mathrm{F}(000)$

Crystal size

Theta range for data collection

Index ranges

Reflections collected

Independent reflections

Completeness to theta $=66.500^{\circ}$

Absorption correction

Max. and min. transmission

Refinement method

Data / restraints / parameters

Goodness-of-fit on $\mathrm{F}^{2}$

Final $\mathrm{R}$ indices [I $>2 \operatorname{sigma}(\mathrm{I})]$

$\mathrm{R}$ indices (all data)

Absolute structure parameter

Largest diff. peak and hole
MDJ072

C10 H9 Br Cl N3 O2

318.56

100(2) K

$1.54178 \AA$

Orthorhombic

$\mathrm{P} 2{ }_{1}{ }_{1}{ }_{1}$

$\mathrm{a}=8.4770(3) \AA$

$\alpha=90^{\circ}$.

$\mathrm{b}=10.9753(4) \AA$

$\beta=90^{\circ}$.

$\mathrm{c}=25.6472(9) \AA$

$\gamma=90^{\circ}$.

2386.15(15) $\AA^{3}$

8

$1.774 \mathrm{Mg} / \mathrm{m}^{3}$

$6.729 \mathrm{~mm}^{-1}$

1264

$0.150 \times 0.050 \times 0.030 \mathrm{~mm}^{3}$

3.446 to $66.631^{\circ}$.

$-10<=\mathrm{h}<=10,-13<=\mathrm{k}<=11,-30<=\mathrm{l}<=27$

27572

$4201[\mathrm{R}($ int $)=0.0308]$

$100.0 \%$

Semi-empirical from equivalents

0.817 and 0.603

Full-matrix least-squares on $\mathrm{F}^{2}$

4201 / 0 / 309

1.042

$\mathrm{R} 1=0.0147, \mathrm{wR} 2=0.0374$

$\mathrm{R} 1=0.0149, \mathrm{wR} 2=0.0375$

$-0.016(5)$

0.270 and -0.221 e. $\AA^{-3}$ 